\title{
OTIMIZAÇÃO DO BLOQUEIO DE PARALELISMO NO CONTROLE DO SISTEMA ELÉTRICO DA ARCELORMITTAL AÇOS PLANOS AMÉRICA DO SUL*
}

Willye Bonfá de Lima ${ }^{1}$ Fernando Dummer Silva ${ }^{1}$

\section{Resumo}

Esse trabalho apresenta aspectos da estratégia utilizada na otimização da Função de Bloqueio de Paralelismo, que é relevante à operação segura do Sistema Elétrico da ArcelorMittal Tubarão. O Bloqueio de Paralelismo assegura que as manobras de fechamento de disjuntores críticos no sistema de média tensão (13,8 kV) sejam feitas sem colocar o Sistema Elétrico da empresa em condições que apresentem risco operacional ou instabilidade elétrica.

Palavras-chave: Utilidades; Supervisão de sistemas elétricos; Bloqueio de paralelismo; Sistemas SCADA.

\section{OPTIMIZATION OF PARALLEL BLOCKAGE OF ARCELORMITTAL FLAT CARBON SOUTH AMERICA'S POWER GRID}

\section{Abstract}

This paper presents aspects of the strategy used for optimizing the Parallelism Blockage Function, that is relevant for the safe operation of the Power Grid of ArcelorMittal Tubarão. The Parallel Blockage ensures that the closing circuit breakers maneuvers at medium voltage level $(13.8 \mathrm{kV})$ are performed without exposing the company's Power Grid to conditions that present operational risks or electrical instability.

Keywords: Utilities; Power grid supervisory; Parallel blockage; SCADA systems.

\footnotetext{
${ }^{1}$ Engenheiro Eletricista, Especialista de Automação, ArcelorMittal Tubarão, Serra, ES, Brasil.
} 


\section{INTRODUÇÃO}

Para atender à demanda de energia dos processos siderúrgicos da ArcelorMittal Tubarão, seu Sistema Elétrico foi projetado para ter a versatilidade necessária para a geração e distribuição de energia elétrica com elevado nível de confiabilidade. $O$ sistema consiste, em linhas gerais, de:

1. Uma rede em alta tensão $(138 \mathrm{kV})$ constituída de diferentes elementos (vide Figura 1):

a. Três Estações Recebedoras ${ }^{1}$, que distribuem a energia dos Geradores Elétricos para as Subestações, e por onde se realiza intercâmbio de fluxo de potência com o sistema elétrico do Espírito Santo. Essas Estações contêm dois conjuntos de barramentos (Barra A, chamada de "Barra da Escelsa" e Barra B, chamada de "Barra de Geração") interligados para prover funções de proteção elétrica às cargas prioritárias. Elas são conectadas ao $\mathrm{SIN}^{2}$ através de duas Linhas de Transmissão ligadas à Subestação ${ }^{3}$ de Pitanga da EDP Escelsa ${ }^{4}$;

b. Sete Geradores Elétricos com capacidade instalada de $472 \mathrm{MW}$ : quatro acionados por CTE's ${ }^{5}$ que queimam os gases subprodutos dos diferentes processos siderúrgicos $\left(\mathrm{COG}^{6}, \mathrm{BFG}^{7}, \mathrm{LDG}^{8}\right.$ e Alcatrão), dois acionados por turbinas de recuperação de calor oriundo do processo da empresa SOL Coqueria, e um acionado por turbina de recuperação de pressão do topo do Alto-Forno 1;

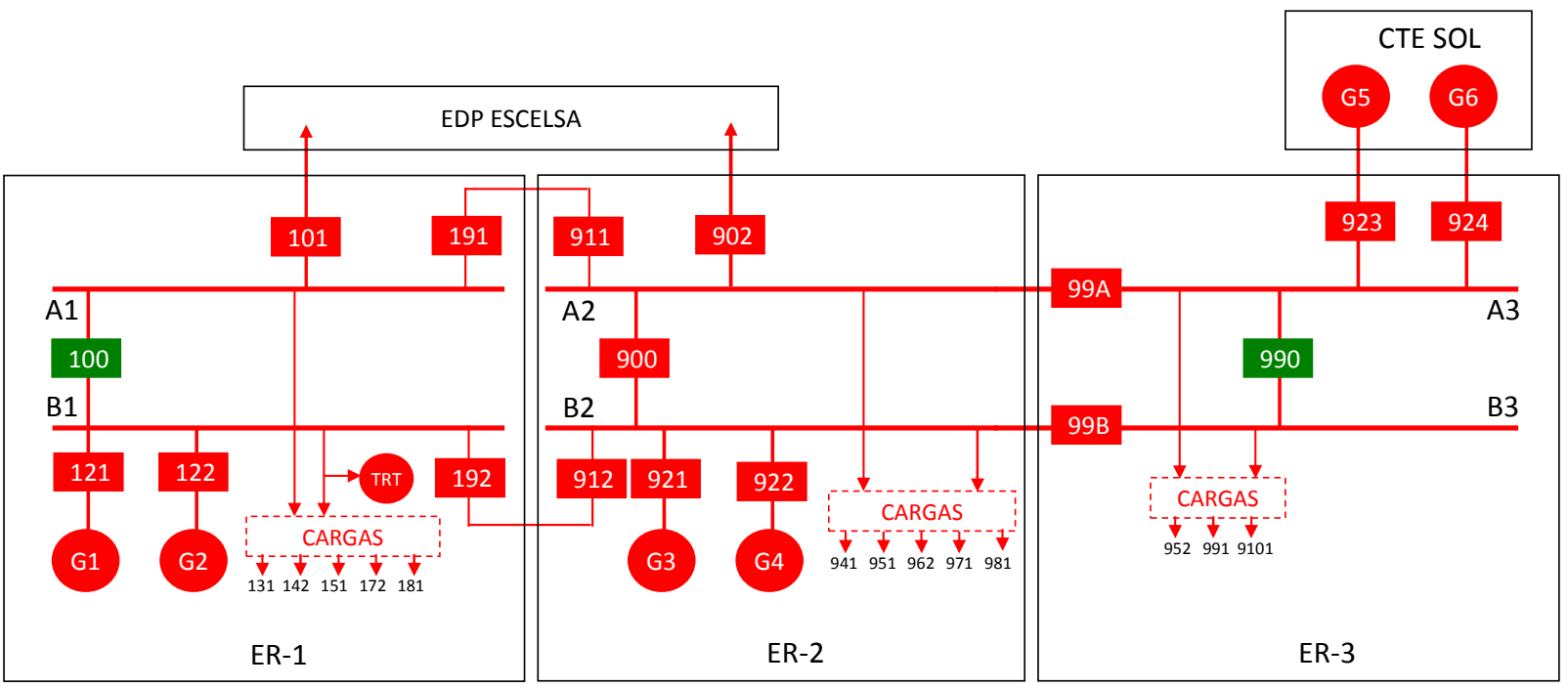

Figura 1 - Diagrama Unifilar ${ }^{9}$ simplificado do Sistema Elétrico em 138 kV.

\footnotetext{
${ }^{1}$ Estação elétrica que opera em $138 \mathrm{kV}$, responsável por receber o afluxo de fontes de energia elétrica e permitir o envio dessa energia para as unidades consumidoras

2 SIN: Sistema elétrico Interligado Nacional

${ }^{3}$ Estação elétrica responsável por receber a potência elétrica em uma tensão menor e a distribuir aos diversos elementos consumidores de energia elétrica, podendo ser desde salas elétricas em baixa tensão a máquinas de grande porte

${ }_{5}^{4}$ Empresa concessionária de energia elétrica que atende a grande parte do Estado do Espírito Santo

${ }^{5}$ Central Termelétrica

${ }^{6}$ COG: Gás de Coqueria

${ }^{7}$ BFG: Gás de Alto-Forno

8 LDG: Gás de Forno Conversor tipo LD de Aciaria

${ }^{9}$ Diagrama simplificado que mostra o sistema elétrico trifásico como se tivesse somente uma fase, para fins de facilitar a visualização
} 
2. Uma rede em média tensão (13,8 kV) composta de diversos elementos (vide a Tela-Mestre do Bloqueio de Paralelismo, na Figura 2), destacando-se:

a. 10 Subestações de alimentação de áreas produtivas;

b. 11 Interligações entre Subestações para manobras e distribuição de cargas;

c. 13 disjuntores ${ }^{10}$ alimentadores de Barra;

d. 13 Barras de distribuição de energia em 13,8 kV.

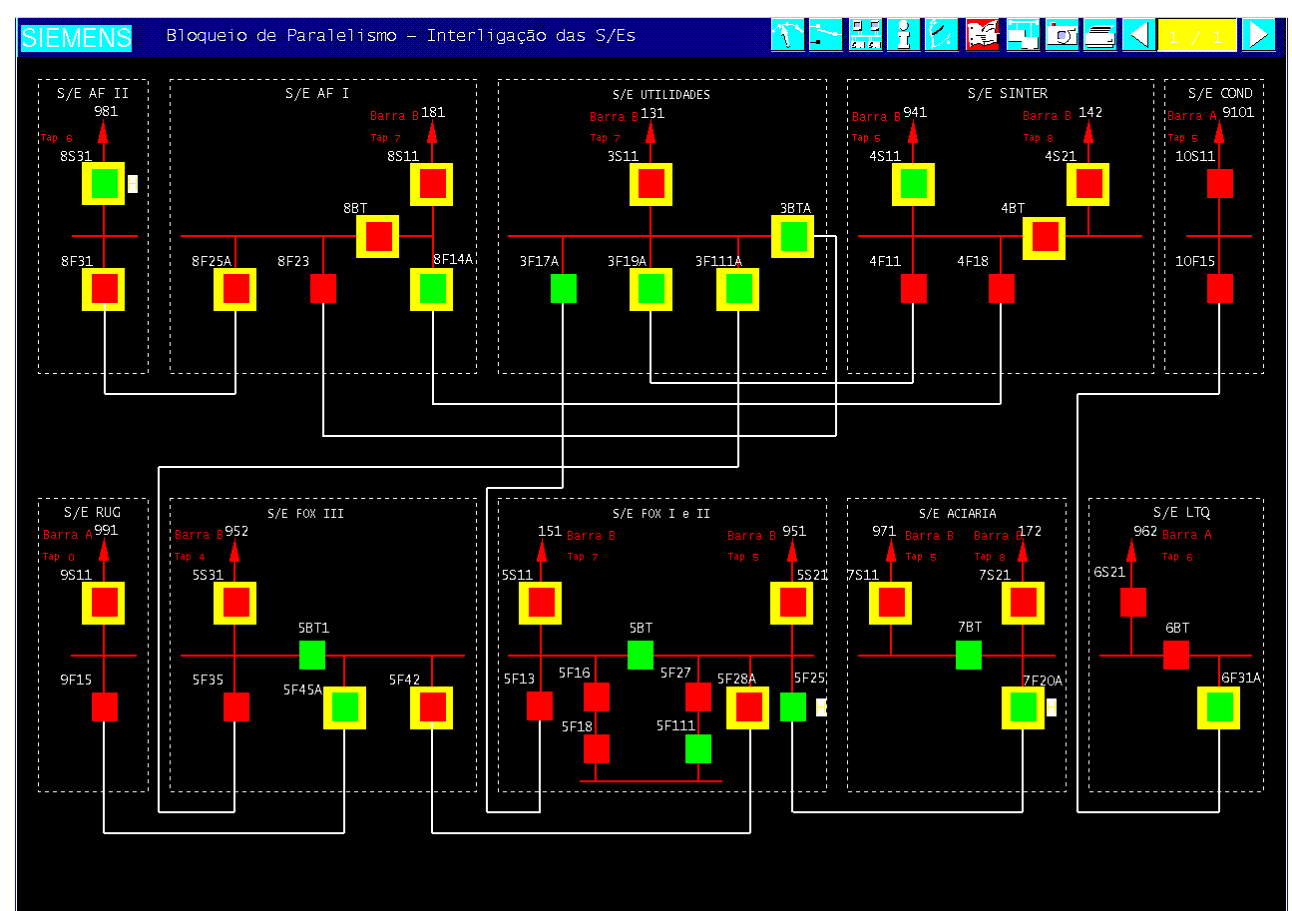

Figura 2 - Diagrama de Interligações em 13,8 kV na Tela-Mestre do Bloqueio de Paralelismo

A supervisão e operação do Sistema Elétrico da ArcelorMittal Tubarão é feita por meio do sistema SCADA ${ }^{11}$ Siemens Power TG®, um sistema EMS ${ }^{12}$ dedicado que incorpora funções específicas para atender às necessidades operacionais do Sistema Elétrico da empresa:

- Controle de Demanda (Compra e Venda de energia elétrica através da interligação com a empresa concessionária);

- Controle de Fator de Potência (Controle do Fator de Potência na interligação com o SIN);

- Controle de Energia (Integralização das Demandas de 15 minutos de energia consumida por para cada uma das cargas consumidoras do Sistema Elétrico);

- Controle de Barramento (Funcionalidades de controle e otimização da distribuição de consumo e geração entre as barras de $138 \mathrm{kV}$ );

- Bloqueio de Paralelismo entre os alimentadores em 13,8 kV;

Ponto focal desse trabalho, o Bloqueio de Paralelismo é uma função do Power TG com a missão de prevenir manobras operacionais que exponham a rede elétrica em 13,8 kV a atuações indesejadas de proteções elétricas nos diversos relés de proteção espalhados pelo sistema.

\footnotetext{
${ }^{10}$ Elemento de manobra que permite energizar ou desenergizar cargas elétricas ao sistema de alimentação, bem como conectar ou desconectar geradores ao sistema elétrico.

11 SCADA: Supervisory Control and Data Acquisition, Sistema de Controle Supervisório e Aquisição de Dados

12 SEM: Energy Management System, sistema SCADA projetado para supervisionar sistemas de geração e distribuição de energia elétrica
} 
Os disjuntores que possuem lógicas de Bloqueio de Paralelismo englobam:

- 13 Disjuntores Alimentadores de Barra de Subestação, a jusante dos transformadores abaixadores;

- 6 Disjuntores Bus-Tie ${ }^{13}$;

- 24 Disjuntores de Interligação, ligados a Linhas de Transmissão em 13,8 kV que conectam uma Subestação a outra, usadas para distribuir cargas e permitir manobras de emergência ou manobras de desenergização para a realização de manutenção com mínimo impacto ao processo siderúrgico.

O Bloqueio de Paralelismo nasceu de um estudo do sistema elétrico para identificar os pontos críticos a serem considerados na topologia do sistema em 13,8 kV. Esse estudo norteou a criação de condicionantes para a realização de manobras de fechamento de disjuntores:

1. Alimentadores de $138 \mathrm{kV}$ na mesma barra: dois disjuntores alimentadores de Subestação que são colocados em paralelo devem ter os respectivos disjuntores alimentadores em $138 \mathrm{kV}$ na mesma Barra, para evitar by-pass das funções de proteção responsáveis por proteger as cargas prioritárias da ArcelorMittal Tubarão contra distúrbios elétricos oriundos do SIN;

2. Paralelismo em Disjuntores Alimentadores: quando qualquer disjuntor em $13,8 \mathrm{kV}$ for fechado, só pode haver dois Alimentadores de Subestação ficando em paralelo (daí vem o nome dessa função) para não haver risco de caminhos preferenciais de corrente;

3. Equalização da Tensão: quando qualquer disjuntor em 13,8 kV for fechado, os tap's dos transformadores alimentadores que se quer colocar em paralelo devem estar iguais para minimizar a diferença de tensão entre os terminais do disjuntor a ser fechado;

4. Quantidade de barras interligadas em série: quando qualquer disjuntor em 13,8 kV for fechado, não pode haver mais do que 3 Barras de Subestação interligadas em série, à exceção de casos bem específicos em que uma quarta barra, de baixa carga e periférica no sistema, pode ser adicionada.

As condicionantes acima estão ilustradas na Figura 3.

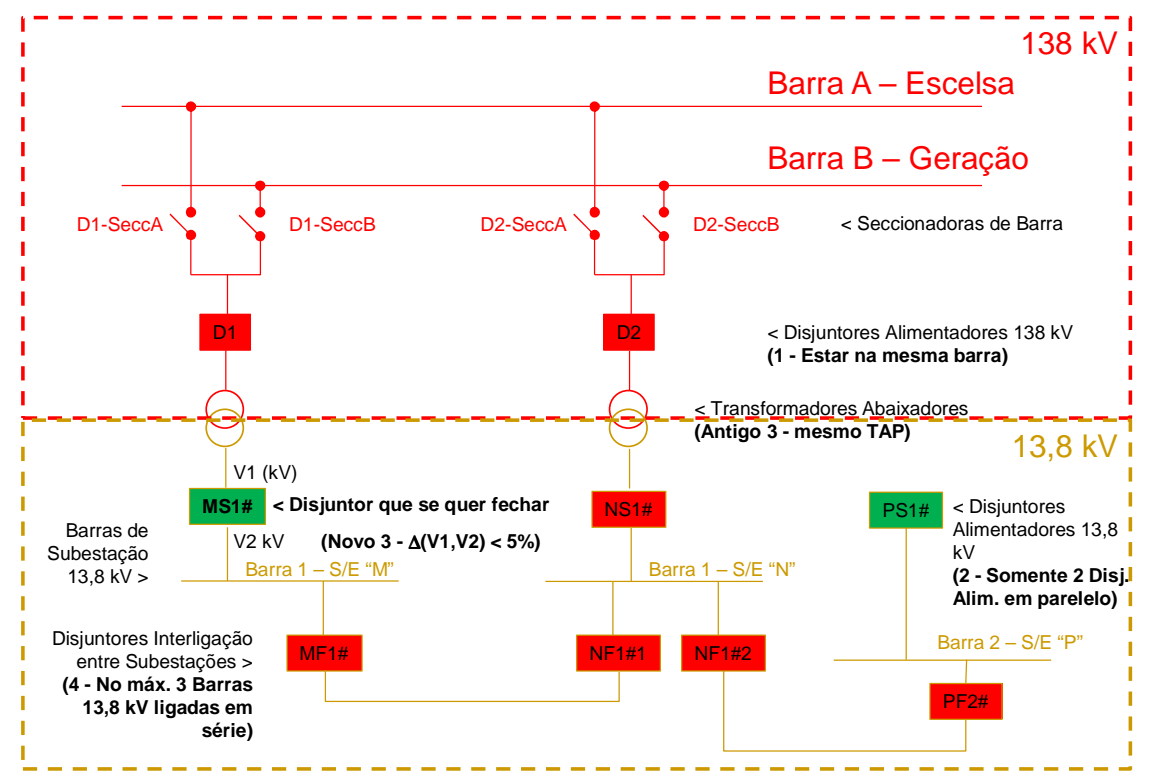

Figura 3 - llustração simplificada de Condicionantes do Bloqueio de Paralelismo

\footnotetext{
${ }^{13}$ Disjuntor que conecta diretamente duas Barras de Subestação
} 


\section{MATERIAIS E MÉTODOS}

\subsection{Identificação da Oportunidade}

Operacional desde a implantação do sistema supervisório, o Bloqueio de Paralelismo apresentava algumas limitações tácitas: novos operadores com menos experiência de campo e na topologia do Sistema Elétrico acabaram tendo maior dificuldade em analisar a topologia quando o Bloqueio de Paralelismo impedia manobras. Tal dificuldade gerava demora na consecução de manobras e causava stress na rotina operacional.

Quando tal dificuldade foi diagnosticada pela equipe de Automação da ArcelorMittal Tubarão, desenvolveu-se um estudo para encontrar formas de facilitar o acesso do operador às informações das Condicionantes do Bloqueio de Paralelismo.

Paralelamente, a Operação do Sistema Elétrico realizou novo estudo de análise elétrica que constatou que a equalização dos tap's dos transformadores abaixadores (Condicionante 3) não assegurava a diferença de tensão adequada para a consecução das manobras. Essa Condicionante foi alterada para assegurar que a diferença de tensão entre os terminais do disjuntor que se quer fechar não seja superior a $5 \%$ da maior tensão.

\subsection{Especificação}

O estudo do problema identificou aspectos que precisavam ser abordados:

- Visualização: O Controlador do Sistema Elétrico só conseguia visualizar, e somente em listagens de pontos de status, os pontos mais gerais do Bloqueio de Paralelismo dos disjuntores (vide o exemplo na Figura 4).

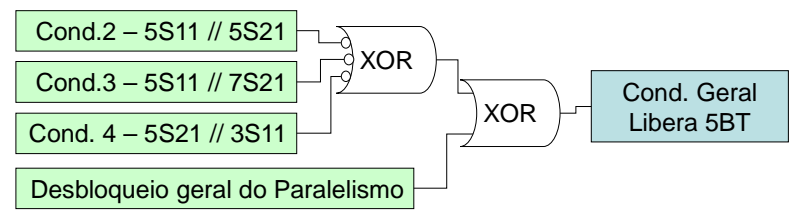

Figura 4 - Nível máximo de detalhe de informação que o Controlador visualizava.

O nível de informação que o Controlador precisa visualizar ia além, pois em cada condição de paralelismo há diversas condições primárias e sub-condições de topologia não óbvias que podem impedir o fechamento, caso não sejam atendidas. A lógica completa para o disjuntor do exemplo, 5BT, pode ser observada na Figura 5. Para cada disjuntor com bloqueio de paralelismo há $\mathrm{PO}^{14}$ 's com os passos a serem efetuados durante a execução das manobras, e a otimização feita não os eximiu de seguir à risca esses padrões. Quando ocorre alguma circunstância não prevista em PO, porém, o Controlador pode avaliar circunstâncias imprevistas visualizando a Tabela-Verdade.

\footnotetext{
${ }^{14}$ PO: Padrão Operacional
} 


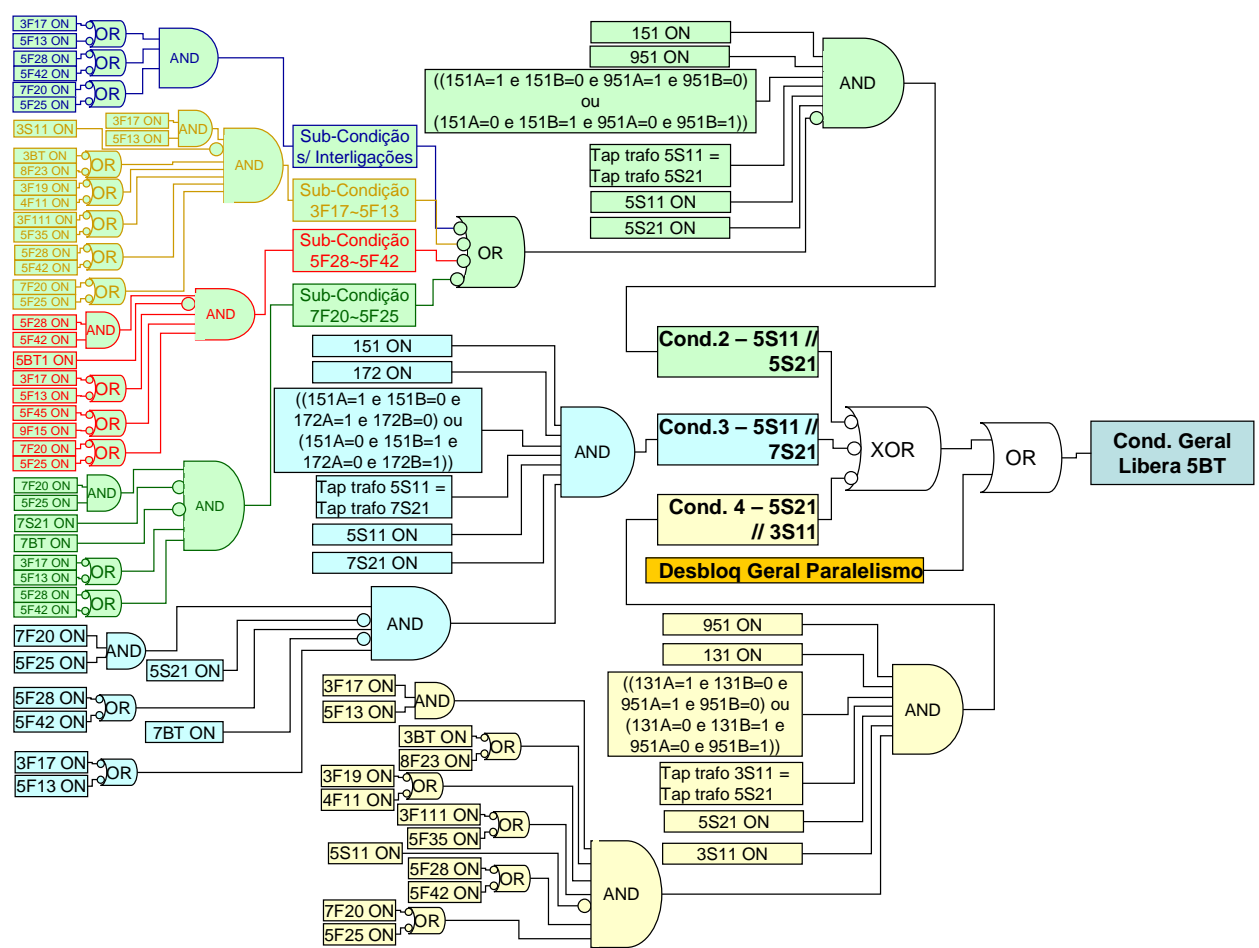

Figura 5 - Lógica completa do Bloqueio de Paralelismo do disjuntor 5BT.

- Interligações entre Subestações: No Bloqueio de Paralelismo, cada interligação entre Subestações tem um Disjuntor-Mestre, elemento de manobra para abrir ou fechar aquela interligação; e um Disjuntor-Escravo na outra ponta, que não deve ser usado como elemento de manobra. Com a ocorrência interligações sendo manobradas fora do padrão, foi preciso aprimorar a forma como o Bloqueio de Paralelismo trata esses elementos:

- O Disjuntor-Mestre permaneceria com a sua lógica de Bloqueio de Paralelismo original, otimizada para ser exibida em Tabela-Verdade;

- O Disjuntor-Escravo passaria a ter uma lógica de Bloqueio para só permitir ser fechado com o Disjuntor-Mestre aberto;

- Diferenças de Tensão: O Controlador do Sistema Elétrico tinha que executar a equalização manual dos tap's ${ }^{15}$ dos transformadores abaixadores, via comando pelo sistema supervisório. Essa condição foi substituída pelo cálculo da diferença entre as tensões de um lado e do outro do disjuntor (Figura 3).

- Barras onde os Disjuntores Alimentadores em 138 kV estão ligados: Era preciso permitir que o Controlador do Sistema Elétrico visualizasse se essa condição estava sendo atendida. Para cada necessidade de comparação da barra em que dois disjuntores "D1" e "D2" se encontram, foi criado um ponto comparando as posições das "seccionadoras de barra" ${ }^{16 ", ~ i n d i c a n d o ~ s e ~ a ~}$ condição "Estão na mesma barra" é verdadeira ou falsa.

A lógica do Bloqueio de Paralelismo de cada disjuntor precisava ser acessível ao operador. A lógica do disjuntor 5BT ilustrado, aberta e otimizada conforme as premissas avaliadas, é mostrada na Figura 6, contendo: pontos discretos dos estados i) de cada interligação; ii) de cada Sub-Condição; iii) de cada disjuntor alimentador $138 \mathrm{kV}$; iv) se estes estão na mesma barra ou não, e v) da diferença de

\footnotetext{
${ }^{15}$ TAP: Posições no comutador de espiras de um transformador que permite modificar dinamicamente, dentro de uma faixa limitada, a tensão em seu secundário.

${ }^{16}$ Elemento de manobra que permite transferir determinada carga de uma barra para outra.
} 
tensão entre os terminais do disjuntor dentro ou não da máxima diferença admissível.

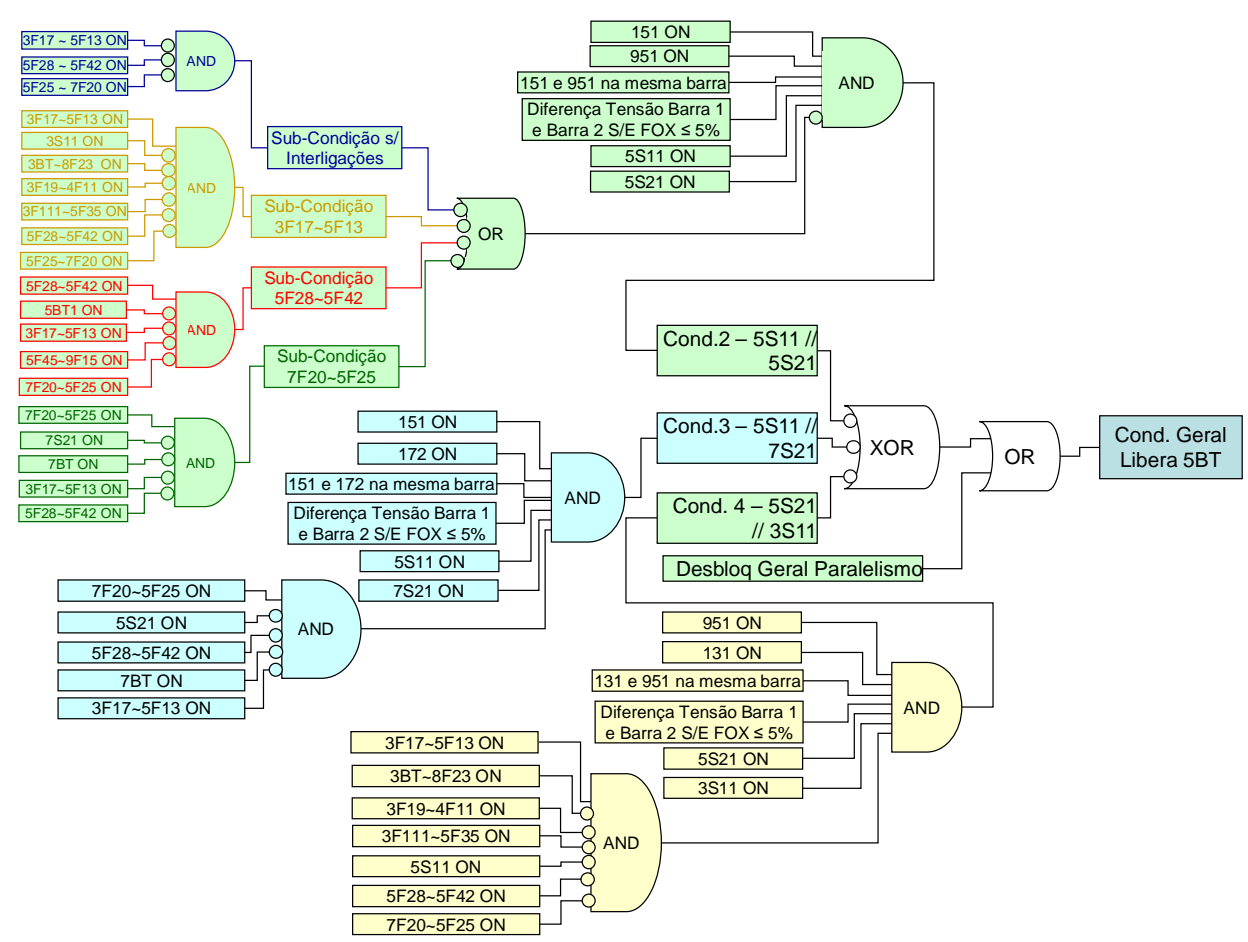

Figura 6 - Lógica de Bloqueio de Paralelismo do disjuntor 5BT após a otimização.

- Navegação e Acesso: Para o Controlador do Sistema Elétrico ter acesso rápido às Tabelas-Verdade de Bloqueio de Paralelismo, na caixa de diálogo quando o operador constata que o disjuntor está bloqueado (Figura 7), foi inserido um botão com o símbolo "//" para indicar "Paralelismo", que ao ser clicado, carrega a Tela-Mestre. O Controlador acessa primeiro essa tela para avaliar as condições gerais de topologia, o que permite ver discrepâncias óbvias. Cada ícone de disjuntor do Diagrama de Interligação, ao ser clicado, abre a respectiva tela da Tabela-Verdade do Bloqueio de Paralelismo.

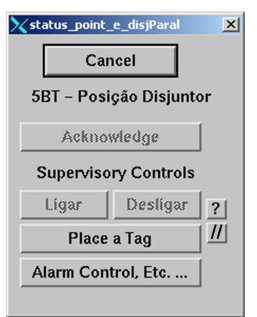

Figura 7 - Caixa de diálogo do comando de Ligar/Desligar disjuntor.

- Layout da Tabela-Verdade: A Tabela-Verdade das lógicas de Bloqueio de Paralelismo deve prover visualização clara da lógica, para que o Controlador do Sistema Elétrico veja que condições ou subcondições bloqueiam (em fundo vermelho) ou liberam (em fundo preto) a manobra. Algumas premissas foram adotadas:

- Cada tela de Tabela-Verdade é segmentada em duas colunas de lógicas desdobradas da condição mais geral à mais detalhada. Cada Condição de Paralelismo foi desdobrada para ser exibida na sequência da esquerda pra direita (Figura 8). 
- Sendo insuficiente uma só coluna, as duas colunas da tela são usadas;

- Sendo insuficiente uma única tela para conter toda a Tabela-Verdade, há uma segunda ou terceira telas de Tabela-Verdade, sendo possível navegar facilmente entre elas;

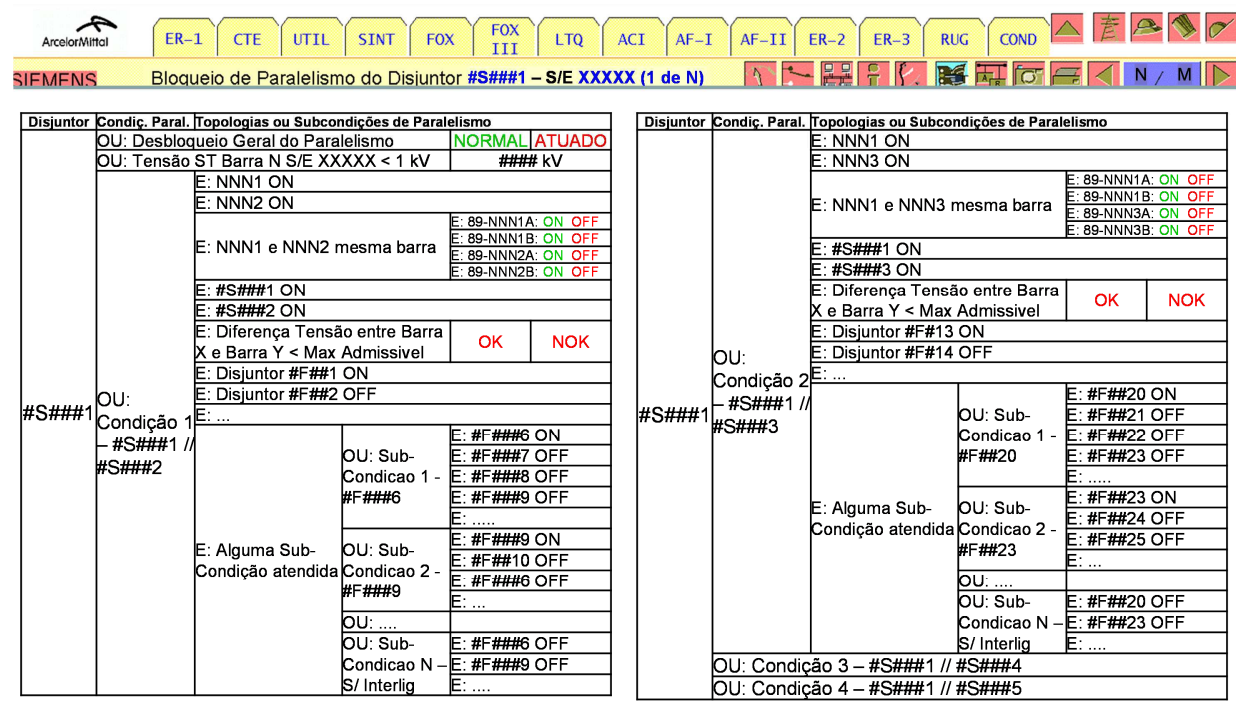

Figura8 - Configuração geral do layout de tela de Tabela-Verdade

Em função da complexidade inerente a cada disjuntor, alguns menos e outros mais complexos, optou-se por se trabalhar em um disjuntor por vez, permitindo prover à Operação do Sistema Elétrico entregas gradativas, devidamente validadas. A Tabela-Verdade do disjuntor exemplificado, 5BT, está na Figura 9.

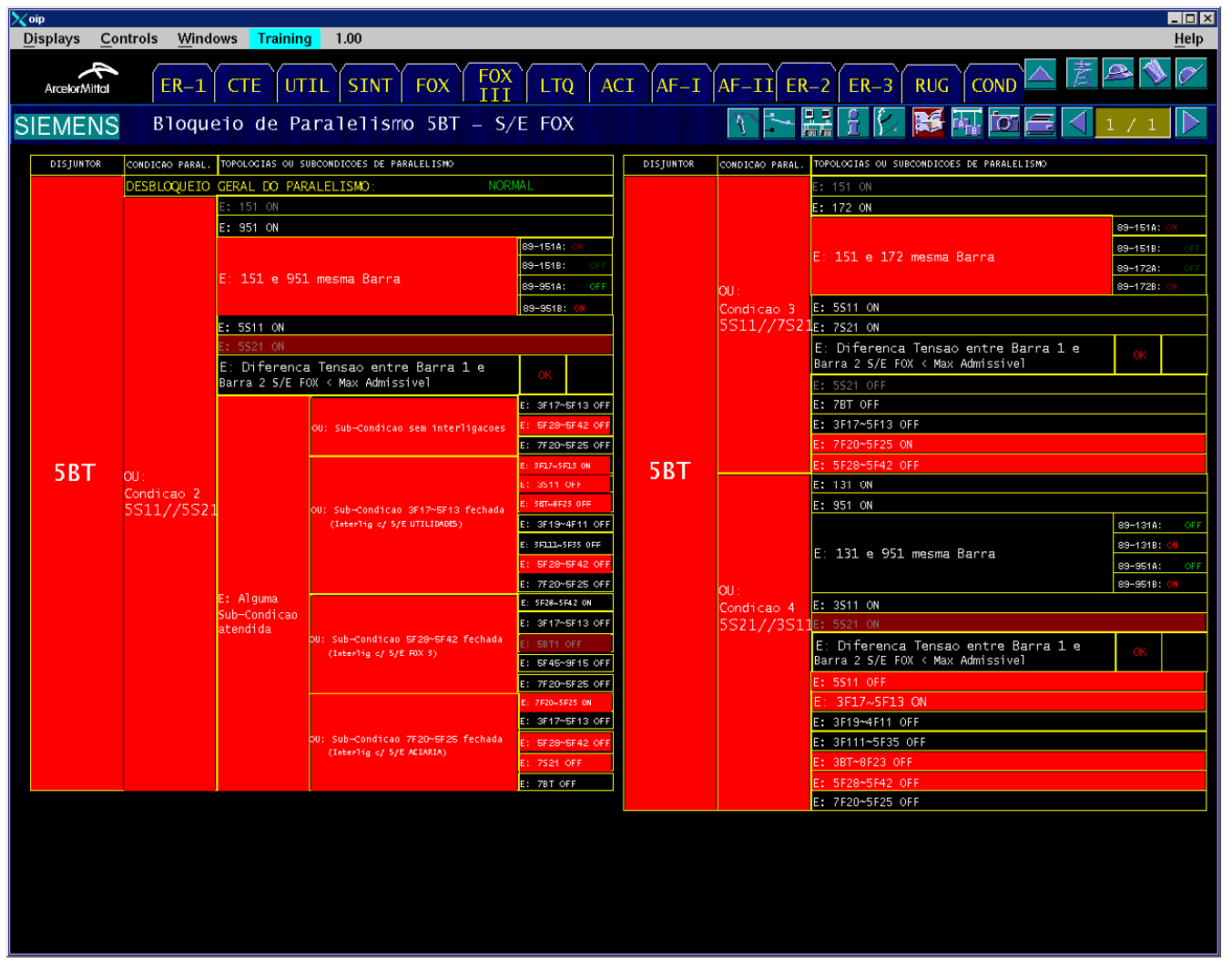

Figura 9 - Tabela-Verdade do Disjuntor 5BT 


\subsection{Desenvolvimento}

Desenvolveu-se um Plano de Trabalho para otimizar o Bloqueio de Paralelismo no disjuntor (O piloto escolhido conforme indicação da própria Operação foi o 5BT):

1. Criar novos pontos no aplicativo de configuração "Siemens SDB"

2. Instalar os pontos criados no DTS ${ }^{18}$;

3. Pré-Implantar os novos pontos para permitir capturar "snapshot" da RTDB ${ }^{19}$ para os testes, sem causar impactos ao Controlador do Sistema Elétrico;

4. Alterar os pontos existentes no SDB e instalar no DTS;

5. Criar a tela de Tabela-Verdade no aplicativo "Siemens IPE"

6. Alterar a tela-mestre para apontar para a tela de Tabela-Verdade criada;

7. Executar o Caderno de Testes para validar a lógica de cada um dos pontos criados ou modificados, no DTS, e corrigir falhas eventuais;

8. Implantar os pontos modificados e a tela criada no RTDB;

9. Validar a Tabela-Verdade com o Controlador do Sistema Elétrico de cada letra de turno da Operação.

A partir dos demais disjuntores, essa sequência foi mantida, o que evitou impactos ao processo e ao sistema supervisório durante a fase de desenvolvimento e testes, causando boa impressão aos operadores.

\subsection{Testes}

A execução bem-sucedida dos testes exigia uma preparação adequada do Caderno de Testes para avaliar a lógica de cada ponto calculado envolvido, quer seja um novo ponto ou um ponto existente que foi modificado. Um aspecto essencial que os testes deveriam contemplar é que tanto a transição adequada dos pontos de status, quanto a animação correta na tela da Tabela-Verdade, deviam ser verificados.

\subsection{Implantação}

Após a realização dos testes com sucesso e a correção de eventuais erros em pontos ou em objetos de animação nas telas de Tabela-Verdade, a implantação foi rápida, simples e exigindo pouco tempo, em comparação com as etapas de planejamento e execução. Não havendo nenhuma reclamação, ocorre a entrega formal do Bloqueio de Paralelismo otimizado daquele disjuntor.

\section{RESULTADOS E DISCUSSÃO}

Como resultado preliminar do projeto, as equipes de operação fizeram algumas constatações, e os comentários giram em torno dos seguintes pontos:

1. Os operadores sentem menos necessidade de usar o Desbloqueio Geral do Paralelismo para efetuar manobras, pois conseguem mapear com facilidade as condições não atendidas;

2. Algumas considerações podem ser feitas do ponto de vista da Automação de Controle de Processos:

\footnotetext{
17 SDB: Source Database Builder

${ }^{18}$ DTS: Dispatcher Training System, ou Sistema de Treinamento de Controladores

19 RTDB: Real-Time Data Base, ou Base de Dados de Tempo-Real

${ }^{20}$ IPE: Interactive Picture Editor
} 
- Não se verificou qualquer degradação na performance do sistema, em função do acréscimo no número de pontos calculados processados pelo RTDB;

- O aumento no número de pontos calculados tem sido feito de forma progressiva, e observou-se que esse acréscimo não é vultoso;

- Alguns pontos de melhoria futura:

- Há oportunidades de melhoria para se otimizar ainda mais a lógica;

- O layout das telas pode ser otimizado para melhorar a visualização;

- Persiste a necessidade de haver o Desbloqueio Geral de Paralelismo, mas o estudo de cada caso de uso do Desbloqueio permitirá no futuro eliminar completamente a necessidade desse botão mesmo em situações atípicas.

\section{CONCLUSÃO}

As perspectivas abertas pelo advento desse projeto, concebida e desenvolvida pela própria equipe de Automação, apontam horizontes para o desenvolvimento de novos recursos que o Power TG possa prover aos Controladores do Sistema Elétrico, na busca de agregar valor à operação do Sistema Elétrico.

Esse projeto de otimização no Bloqueio de Paralelismo nasceu do diagnóstico feito da condição de trabalho rotineira dos Controladores do Sistema Elétrico, o que reforça a importância de o profissional de Automação estar consistentemente participando dos projetos, estudos, atuações em incidentes e na rotina dos processos nas áreas-cliente.

As necessidades de aprimoramento e evolução dos Sistemas de Otimização de Controle de Processo surgem precisamente nas áreas-cliente. Algumas dessas necessidades não são verbalizadas, ainda que subjetivamente sentidas pelos operadores. Portanto, eles precisam ser ouvidos e atendidos adequadamente, para que a Automação de Controle de Processos seja eficaz e agregue valor à geração de resultados para as partes interessadas no negócio da ArcelorMittal Tubarão.

\section{BIBLIOGRAFIA}

1 Siemens. ScriptIDE/ScriptCALC Developer's Guide. 2001. Document Number 80000451-00000, Document Number 8000-0451-00000, Software Version 7.3, Document Revision A

2 Siemens. Guia do Instrutor para Interface de Construção de Banco de Dados Fonte (Telegyr Source Database Builder). 2001. Número do Documento: 8000-0000-00000. Versão do Software: 7.3. Revisão do Documento: A

3 Siemens. Interactive Picture Editor Reference Manual. 2006. Document No. PTG-041100000-RM-IPE, Document Revision 2.0. 